\title{
INTERNET PHOTOGRAMMETRY FOR INSPECTION OF SEAPORTS
}

\author{
Zygmunt Paszotta ${ }^{1}$ \\ Malgorzata Szumilo' \\ Jakub Szulwic ${ }^{2}$ \\ ${ }^{1}$ Univeristy of Wamia and Mazury in Olsztyn, Poland \\ ${ }^{2}$ Gdansk University of Technology, Poland
}

\begin{abstract}
This paper intends to point out the possibility of using Internet photogrammetry to construct 3D models from the images obtained by means of UAVs (Unmanned Aerial Vehicles). The solutions may be useful for the inspection of ports as to the content of cargo, transport safety or the assessment of the technical infrastructure of port and quays. The solution can be a complement to measurements made by using laser scanning and traditional surveying methods. In this paper the authors recommend a solution useful for creating 3D models from images acquired by the UAV using non-metric images from digital cameras. The developed algorithms, created and presented software allows to generate $3 D$ models through the Internet in two modes: anaglyph and display in shutter systems. The problem of 3D image generation in photogrammetry is solved by using epipolar images. The appropriate method was presented by Kreiling in 1976. However, it applies to photogrammetric images for which the internal orientation is known. In the case of digital images obtained with non-metric cameras it is required to use another solution based on the fundamental matrix concept, introduced by Luong in 1992. In order to determine the matrix which defines the relationship between left and right digital image it is required to have at least eight homologous points. To determine the solution it is necessary to use the SVD (singular value decomposition). By using the fundamental matrix the epipolar lines are determined, which makes the correct orientation of images making stereo pairs, possible. The appropriate mathematical bases and illustrations are included in the publication.
\end{abstract}

Keywords: inspection of wharf, security of seaports, registration of cargo ships, UAV (unmanned aerial vehicles)

\section{INTRODUCTION}

During recent years the use of unmanned aerial vehicles (UAVs) has increased significantly. UAVs with the capability of photogrammetric data acquisition opens various new applications in aerial and terrestrial photogrammetry and also introduces low-cost alternatives to the classical photogrammetry $[25,26]$. An extensive overview of the evolution and the state-of-the-art of photogrammetry by using UAV is given by Eisenbeiss and Unger [4, 31]. The authors describe early developments and present a review on UAVs for photogrammetric topics like flight planning, image acquisition and orientation and data processing. In this paper the authors focus on generating 3D images from images taken from UAVs through the Internet.

The solution is based on the website photogrammetry and can be used for inspection of ports, wharves, coasts, and ships. Construction of stereoscopic model, optionally enriched with scale imaging, allows for a correct identification and spatial observations. A tool like a photogrammetry may be useful for evaluating and measuring tanks, silos and special constructions in the ports $[1,7,12-15,17,28,30]$. The main limitation of the method is range of UAV and availability of satellite positioning system [11]

There are also used groups of drones which take images synchronously, can analyze filling?, moving the autonomous objects and inspect moving and vibrating parts of vessels.

Emergency service might be another area of the potential application where rescue teams might need quick and portable access to UAV data. The examining stereoscopic model for the purpose of identifying objects and judging their significance is much easier than plane image interpretation $[21,22]$.

In traditional photogrammetry (which is based on photogrammetric images) generating stereoscopic models is a public process. The method of analogue spatial visualization in stereoscopic entertainment mediums such as Kaiserpanorama (consisted of sets of stereo slides and a multi-station viewing apparatus) has been known since the 
mid $19^{\text {th }}$ century. In the literature source [20] four conditions are mentioned for the analogue way of obtaining the $3 \mathrm{D}$ effect. They refer to:

- parallactic angle,

- the difference of scales of the left and right image,

- separation of transmission channels for left and right images (sending the "right eye" image to the right eye and the "left eye" image to the left eye),

- watching pictures on the epipolar plane.

When all the above mentioned conditions are met, to obtain 3D images from non-metric images will be possible. The first condition is satisfied if the images acquired during the photogrammetric flight have appropriate forward overlap. The images taken when the UAVs have only turned around, are improper. In this case the base which represents the distance between the projection centres of both images is too small. Moreover, these are not overlapping images.

The second condition (scale stability) should be guaranteed for in-flight plane. The next condition depends on the selection of 3D display techniques. In this paper the anaglyph method and active shutter 3D systems are implemented. The theoretical basis of the fourth condition is described in detail in this work beneath.

A breakthrough in the process of $3 \mathrm{D}$ image generation was made in 1976 when Kreiling developed a method of generating epipolar images $[3,9,27,33]$. However, it is possible to project stereogram images onto the common plane if the camera constants and the elements of relative orientation are known. Generating and superimposing component digital images is also a public process.

Many functions and actions which perform measurements and computations, must be programmed. It appears that it is possible to generate $3 \mathrm{D}$ images (the pair of images which relative orientation is known and which could be visualized as a stereoscopic model) with the use of the idea of anaglyphic images on the Internet, interactively. It is possible to reach such solution on an ordinary computer, but the quality of the so obtained three-dimensional image is not sufficient. The generation and visualization of $3 \mathrm{D}$ images by using shutter glasses is a more advanced approach. Both of the mentioned solutions work as an Internet application in JAVA and use client-server technology, which in practical terms means communication between applets and the servlet. This paper presents the theoretical fundamentals for the adopted solution, together with a plan for its implementation. Since a few years ago (from about 2001) up to now these authors have developed interactive Internet photogrammetric applications $[22,23]$. The described research is a summary of work performed on non-metric images.

Due to the use of JAVA software, the presented solution might be used in most of the contemporary web browsers. The authors propose a solution which is available through web browsers as a portable tool and convenient alternative to standalone desktop applications. The use of Internet solution allows to make advantage of all the merits of this technology, such as universal access to the data, simultaneous use by multiple users.

\section{THEORETICAL FUNDAMENTALS}

The concept of a fundamental matrix is introduced, assuming that homologous points lie on the epipolar plane as the starting point.

According to Fig. 1, the following equation must be satisfied:

$$
\mathbf{r}_{t}{ }^{\prime} \cdot\left(\mathbf{b} \times \mathbf{r}^{\prime}\right)=0
$$

where:

$$
\mathbf{b} \times \mathbf{r}^{\prime}=\left|\begin{array}{ccc}
\mathbf{i} & \mathbf{j} & \mathbf{k} \\
b_{x} & b_{y} & b_{z} \\
r_{x}^{\prime} & r_{y}{ }^{\prime} & r_{z}{ }^{\prime}
\end{array}\right|=\left[\begin{array}{c}
0-b_{z} r_{y}{ }^{\prime}+b_{y} r_{z}{ }^{\prime} \\
b_{z} r_{x}{ }^{\prime}+0-b_{x} r_{z}{ }^{\prime} \\
-b_{y} r_{x}{ }^{\prime}+b_{x} r_{y}{ }^{\prime}-0
\end{array}\right]=\left[\begin{array}{ccc}
0 & -b_{z} & b_{y} \\
b_{z} & 0 & -b_{x} \\
-b_{y} & b_{x} & 0
\end{array}\right]\left[\begin{array}{l}
r_{x}{ }^{\prime} \\
r_{y}{ }^{\prime} \\
r_{z}^{\prime}{ }^{\prime}
\end{array}\right]=\mathbf{B ~ \mathbf { r } ^ { \prime }}
$$

If $\mathbf{Q}$ is the rotation matrix for vector $\mathbf{r}^{\prime \prime}$ to the object coordinate system $\left(\mathrm{O}_{1}, \mathrm{x}, \mathrm{y}, \mathrm{z}\right)$, i.e.:

$$
\mathbf{r}_{t}{ }^{\prime}=\mathbf{Q} \mathbf{r}^{\prime \prime}
$$

then the scalar product is given as :

$$
\left(\mathbf{r}_{t}^{\prime \prime}\right)^{T} \mathbf{B} \mathbf{r}^{\prime}=\left(\mathbf{r}^{\prime \prime}\right)^{T} \mathbf{Q}^{T} \mathbf{B} \mathbf{r}^{\prime}=0 .
$$

Let the two cameras be characterized by two calibration matrices $\mathbf{A}_{1}$ and $\mathbf{A}_{2}$ (containing only the principal distance):

$$
\mathbf{r}_{p}^{\prime}=\mathbf{A}_{1} \mathbf{r}^{\prime} \quad \mathbf{r}_{p}^{\prime \prime}=\mathbf{A}_{2} \mathbf{r}^{\prime \prime}
$$

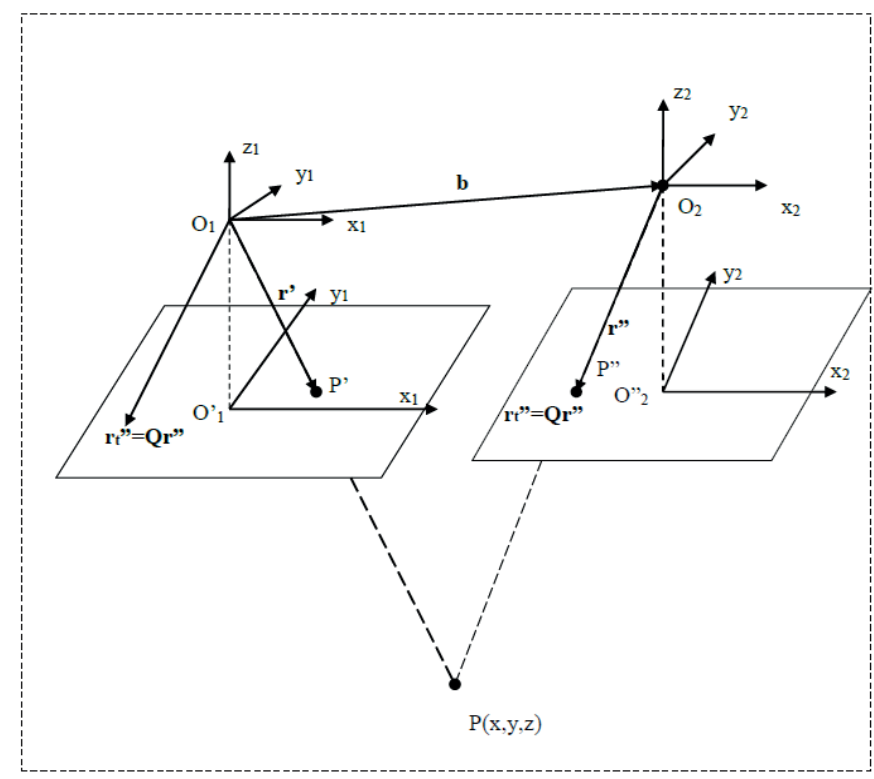

Fig. 1. Geometrical relationships on a stereogram

therefore:

$$
\left(\mathbf{r}_{p}{ }^{\prime}\right)^{T} \mathbf{A}_{2}^{T} \mathbf{Q}^{T} \mathbf{B} \mathbf{A}_{1}^{-1} \mathbf{r}_{p}{ }^{\prime}=0
$$


Let $\mathbf{F}=\mathbf{A}_{2}^{T} \mathbf{Q}^{T} \mathbf{B} \mathbf{A}_{1}^{-1}$ to be called a fundamental matrix. It helps to determine epipolar lines. For the point with the coordinates $\mathbf{r}_{p}$ " on the right image, the epipolar line on the left image is described by the following equation (in homogeneous coordinates):

$$
\mathbf{r}_{p} " \cdot \mathbf{u}^{\prime \prime}=0, \text { where } \mathbf{u}^{\prime \prime}=\mathbf{F} \mathbf{r}_{p}{ }^{\prime}
$$

The shape of the matrix $\mathbf{F}=\mathbf{A}_{2}^{T} \mathbf{Q}^{T} \mathbf{B} \mathbf{A}_{1}^{-1}$ is $3 \times 3$. There are nine coefficients to determine. One of them is connected with scale factor and hence it could be reduced, which makes that only eight coefficients have to be calculated. To determine them, at least eight homologous points are needed. This algorithm was introduced by Longuet-Higgins [16, 24]. Therefore Eq. (6) can be written as follows :

$$
\left(\mathbf{r}_{p}{ }^{\prime \prime}\right)^{T} \mathbf{F} \mathbf{r}_{p}{ }^{\prime}=0
$$

All the epipolar lines on a given image plane, either left or right, go through one epipole. They make up a pencil of lines which meet in the epilpole (epipolar pencil). If they are marked $\mathbf{e}_{p}{ }^{\prime}$ and $\mathbf{e}_{p}{ }^{\prime}$, respectively, then the following relationships are satisfied [6]:

$$
\mathbf{F} \mathbf{e}_{p}{ }^{\prime}=\mathbf{0}, \mathbf{e}_{p}{ }^{"} \mathbf{F}=\mathbf{0}
$$

\section{IMPLEMENTATION OF THE APPLICATION}

Implementation of the method in question requires the proper software and execution of various operations both on the part of the client and of the server. Subsequent stages of elaboration of the non-metric stereo pair ( beginning from measurement of homologous point to visualization of the $3 \mathrm{D}$ image) are presented in the complete activity diagram - Fig. 2.

Determination of a fundamental matrix is the first, decisive and most important point in the process of creating $3 \mathrm{Dl}$ images from non-metric images. Therefore in this section we focus on the method of its calculation. Let's assume that the coordinates of at least eight homologous points are measured. Then Eq. (8) can be applied and written as follows :

$$
\mathbf{M f}=\mathbf{0}
$$

where: $\mathbf{f}=\left[f_{11}, f_{\mathrm{2}}, f_{\mathrm{B}}, f_{2}, f_{2}, f_{3}, f_{3}, f_{3}, f_{3}\right]^{I}$ vectors of ordered elements of matrix $\mathbf{F}$ and each row of matrix $\mathbf{M}$ equals $\left[x_{2} y_{2}, y_{2} x_{1}, x_{1}, x_{2} y_{1}, y_{2} y_{1}, y_{1}, x_{2}, y_{2}, 1\right]$ for $\mathbf{r}_{p} "=\left[x_{2}, y_{2}, 1\right]$ and $\mathbf{r}_{p}{ }^{\prime}=\left[x_{1}, y_{1}, 1\right]$

A system of homogeneous equations with nine unknown elements of matrix $F$ is obtained. If the rank of matrix $M$, equal to $k$, is lower than nine then it has an infinite number of non-zero solutions, depending on $\mathrm{k}$ parameters. To find the solution of the system we apply singular value decomposition (SVD). It has a particularly useful property, namely, that the rank $(\mathrm{M})$ is equal to the number of nonzero values of particular matrices, and so on [= also ? ] the number of non-zero elements on the diagonal of diagonal matrix V. In order to obtain $\operatorname{rank}(M)=8$, or rather rank $\left(M^{\prime}\right)=8$, the least singular value should be equal to zero. If our measurements of the coordinates of homologous points were correct, there should be a sharp jump between the eighth and the ninth singular value. The corrected matrices $\mathrm{V}$ and $\mathrm{M}$ will be marked $\mathrm{V}^{\prime}$ and $\mathrm{M}^{\prime}$, respectively, where :

$$
\mathbf{M}^{\prime}=\mathbf{S}^{\prime} \mathbf{V}^{\prime} \mathbf{D}^{\prime T}
$$

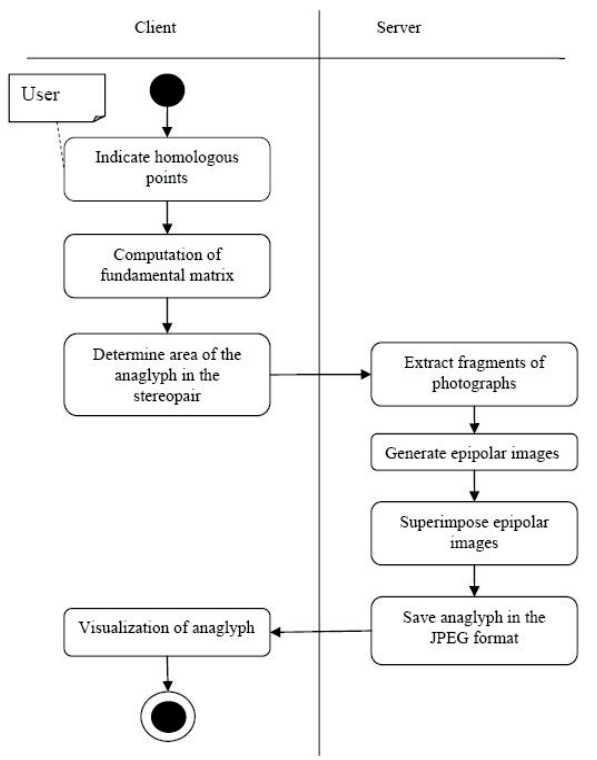

Fig. 2. Activity diagram in the process of generating anaglyphic 3D images

The order of matrix $\mathbf{M}^{\prime}$ is now 8, and the system of equations has the following form:

$$
\text { M'f }=\mathbf{0}
$$

Adopting one unknown as a parameter, we obtain a homogeneous system which will be solved with the use of SVD. To achieve an unambiguous solution, 8 points are needed. For a larger number of points, the condition $\mathbf{M} \mathbf{f}-\mathbf{c}=0$ is replaced with: $\mathbf{r}^{2}=(\mathbf{M} \mathbf{f}-\mathbf{c})^{2}=$ min which will be noted as follows :

$$
\mathbf{M}^{\prime} \mathbf{f} \approx \mathbf{c}
$$

On the basis of Eq. (11) and Eq. (13) we have :

$$
\mathbf{V}^{\prime} \mathbf{D}^{\prime^{T}} \mathbf{f} \approx \mathbf{S}^{\mathbf{T}^{T}} \mathbf{c}
$$

By marking

$$
\mathbf{S}^{\mathbf{t}^{T}} \mathbf{c}=\mathbf{g}, \quad \mathbf{D}^{\prime T} \mathbf{f}=\mathbf{p},
$$

we have

$$
\mathbf{V}^{\prime} \mathbf{p} \approx \mathbf{g} .
$$


Finally, the following solution is obtained

$$
\mathbf{f}=\mathbf{D}^{\prime} \mathbf{p} \text {. }
$$

The Internet application is implemented in a client-server architecture where the client is a web browser. The presented software allows to generate three-dimensional images from non-metric images over the Internet in two modes: anaglyph and shutter system. The detailed description of selected 3D display techniques is presented beneath in this paper.

The flowchart of the application operation is based on the possibility to download wirelessly (e.g. by using the Internet connection through the cellular network, Wi-Fi) the nonmetric digital images that are stored on the application server. It is possible to automate the process of selecting images for stereo pairs, but this condition is not a subject matter of this publication. The authors suggest that it is even purposeful to use the photogrammetric operator's (human) experience, who, by the selection of the proper image, makes it possiblefor the server application - to generate $3 \mathrm{D}$ models with a better quality and thus suitability for the end user. With this solution, the user of client application will be able to obtain a 3D model useful for analyses related to verification of maritime space.

The concept of Internet photogrammetry used to develop $3 \mathrm{D}$ models from digital images obtained from UAVs, has a significant economic advantage over the solutions based on a license assigned to the end client's computer. In the proposed solution the server application is critical, while client application ran through a web browser is the so-called "thin client" and may be used by a broader group of users (non-professionals in the field of photogrammetry, who may stay in different places away) who can simultaneously assess , in terms of another, their own expertise and knowledge.

\section{THE EXAMPLE OF ONLINE 3D IMAGE GENERATION}

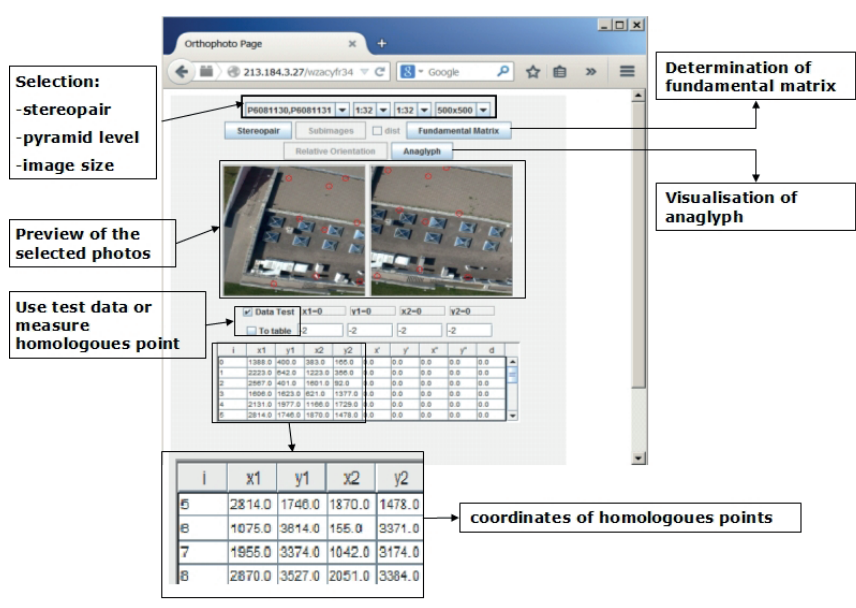

Fig. 3. A detailed description of elements in the application window
The selection of images is the first issue. Data which are necessary for constructing 3D image, obtained from several sources:

-images and their fragments - from a directory of images on the data server,

- parameters of images (size, resolution)

- from the database and other data,

- coordinates of homologous points and

- initial parameters of process of 3D image generation, have been delivered to the client.

The application has started working on the client side after downloading the above mentioned website. The user has had to select the stereo pair and appropriate image pyramid level, indicate the area of interest on the chosen images and send , to application server, request for preparation of a part of the image. Later on, the web browser windows looked like in Fig. 3.

It is possible to install one's stereogram on the server and run the whole process. However, it is a more profitable option to start with using the images which are already there and the attached text data (set of homologous points). There are images taken by OLYMPUS PEN E-P2 camera from microdrones md4-1000 UAV. The size of each image is 3084 rows by 4096 columns.

The camera specification is available on the website http:// goo.gl/Q8J27l and http://goo.gl/salv8t. Therefore, we select a stereogram and data as given in Fig. 3. The data can be modified by using a series of reduced-resolution versions of an image formed by smoothing and subsampling of the original left - and - right image, and stored on the server. Subsequently, we determine the matrix M from formula (10). The values of its elements are displayed in a separate window. They are given in Tab. 1 .

For inspection in the ports, other UAVs equipped with e.g. a thermal camera and based on different configurations [2], can be used.

Tab. 1. Elements of the matrix $\mathbf{M}=\left[m_{i j}\right]$

\begin{tabular}{|r|r|r|r|r|r|r|r|r|r|}
\hline$i j$ & \multicolumn{1}{c|}{1} & \multicolumn{1}{c|}{2} & \multicolumn{1}{c|}{3} & \multicolumn{1}{c|}{4} & \multicolumn{1}{c|}{5} & \multicolumn{1}{c|}{6} & \multicolumn{1}{l|}{7} & \multicolumn{1}{c|}{8} & 9 \\
\hline 1 & 531604 & 153200 & 383 & 229020 & 66000 & 165 & 1388 & 400 & 1 \\
\hline 2 & 2718729 & 785166 & 1223 & 791388 & 228552 & 356 & 2223 & 642 & 1 \\
\hline 3 & 4109767 & 642001 & 1601 & 236164 & 36892 & 92 & 2567 & 401 & 1 \\
\hline 4 & 997326 & 1007883 & 621 & 2211462 & 2234871 & 1377 & 1606 & 1623 & 1 \\
\hline 5 & 2484746 & 2305182 & 1166 & 3684499 & 3418233 & 1729 & 2131 & 1977 & 1 \\
\hline 6 & 5262180 & 3265020 & 1870 & 4159092 & 25805888 & 1478 & 2814 & 1746 & 1 \\
\hline 7 & 166625 & 560170 & 155 & 3623825 & 12182794 & 3371 & 1075 & 3614 & 1 \\
\hline 8 & 2037110 & 3515708 & 1042 & 6205170 & 10709076 & 3174 & 1955 & 3374 & 1 \\
\hline 9 & 5886370 & 7233877 & 2051 & 9712080 & 11935368 & 3384 & 2870 & 3527 & 1 \\
\hline
\end{tabular}

Tab. 2. Elements of the orthogonal matrix $\mathbf{S}=\left[S_{i j}\right]$

\begin{tabular}{|c|c|c|c|c|c|c|c|c|c|}
\hline$i j$ & 1 & 2 & 3 & 4 & 5 & 6 & 7 & 8 & 9 \\
\hline 1 & -0.0136 & 0.0504 & -0.0540 & 0.0540 & 0.0703 & 0.6944 & 0.5970 & -0.3567 & 0.1535 \\
\hline 2 & -0.0593 & 0.2553 & -0.3233 & 0.0346 & 0.3502 & -0.2050 & 0.2053 & -0.5470 & -0.5653 \\
\hline 3 & -0.0563 & 0.3586 & -0.6906 & -0.2317 & 0.1023 & -0.1970 & 0.1189 & 0.3923 & 0.3469 \\
\hline 4 & -0.1280 & 0.0358 & 0.0888 & 0.6021 & 0.1723 & -0.1015 & 0.5083 & 0.5125 & -0.2257 \\
\hline 5 & -0.2205 & 0.1709 & 0.1079 & 0.5024 & 0.0532 & -0.2630 & 0.0635 & -0.4260 & 0.6329 \\
\hline 6 & -0.2461 & 0.4975 & -0.1514 & 0.3154 & -0.4869 & 0.2520 & -0.4624 & 0.0293 & -0.2329 \\
\hline 7 & -0.4247 & -0.6424 & -0.5021 & 0.1071 & -0.1953 & -0.2600 & 0.0945 & -0.1668 & 0.0287 \\
\hline 8 & -0.4860 & -0.2120 & 0.1059 & 0.0199 & 0.2776 & -0.5475 & -0.4797 & 0.2687 & -0.1678 \\
\hline 9 & -0.6716 & 0.2608 & 0.3315 & -0.4625 & -0.0027 & 0.2290 & 0.3182 & -0.0418 & 0.0415 \\
\hline
\end{tabular}


Tab. 3. Elements of the orthogonal matrix $\mathbf{D}=\left[d_{i j}\right]$

\begin{tabular}{|c|c|c|r|r|r|r|r|r|c|}
\hline$I j$ & 1 & 2 & 3 & \multicolumn{1}{c|}{4} & 5 & 6 & 7 & 8 & 9 \\
\hline 1 & -0.2785 & 0.7076 & -0.6486 & 0.0325 & -0.0009 & 0.0002 & -0.0001 & 0.0000 & 0.0000 \\
\hline 2 & -0.3141 & 0.3696 & 0.5022 & -0.7159 & 0.0017 & 0.0000 & 0.0013 & 0.0000 & 0.0000 \\
\hline 3 & -0.0001 & 0.0003 & -0.0003 & 0.0005 & 0.2581 & -0.9571 & -0.0792 & -0.1052 & 0.0018 \\
\hline 4 & -0.5000 & 0.2219 & 0.4907 & 0.6782 & -0.0014 & 0.0000 & -0.0013 & 0.0000 & 0.0000 \\
\hline 5 & -0.7575 & -0.5599 & -0.2938 & -0.1627 & 0.0002 & 0.0000 & -0.0001 & 0.0000 & 0.0000 \\
\hline 6 & -0.0002 & -0.0001 & -0.0001 & 0.0014 & 0.0499 & -0.1221 & 0.6800 & 0.7212 & -0.0049 \\
\hline 7 & -00002 & 0.0003 & -0.0006 & 0.0018 & 0.9420 & 0.2529 & -0.1714 & 0.1392 & -0.0019 \\
\hline 8 & -0.0003 & -0.0001 & -0.0002 & 0.0018 & 0.2088 & 0.0714 & 0.7085 & -0.6703 & 0.0041 \\
\hline 9 & 0.0000 & 0.0000 & 0.0000 & 0.0000 & 0.0007 & 0.0013 & -0.0003 & 0.0068 & 1.0000 \\
\hline
\end{tabular}

Tab. 4. Values on the diagonal of the matrix $\mathbf{V}=\left[v_{i j}\right]$

\begin{tabular}{|c|c|c|c|c|}
\hline$v_{11}$ & $v_{22}$ & $v_{33}$ & $v_{44}$ \\
\hline 26517003.4290 & 8860122.3556 & 3241135.9293 & 742286.8409 \\
\hline$v_{55}$ & $v_{66}$ & $v_{77}$ & $v_{88}$ & $v_{99}$ \\
\hline 1432.5705 & 178.1029 & 35.8178 & 1.5759 & 0.0092 \\
\hline
\end{tabular}

The matrix $\mathbf{M}$ is distributed against the singular values. Tab. 2, 3, 4 present the solution of singular value decomposition (SVD) of the matrix $\mathbf{M}$.

Let the element v99 be equal to zero; according to formulae (13) - (17) we have:

Tab. 5. Elements of the matrix $\mathbf{F}=\left[f_{i j}\right]$

\begin{tabular}{|c|c|c|c|}
\hline$i \quad j$ & 1 & 2 & 3 \\
\hline 1 & -0.00023 & -0.00551 & 17.79343 \\
\hline 2 & 0.00688 & 0.00030 & -49.46823 \\
\hline 3 & -18.51439 & 41.08829 & 10000.00000 \\
\hline
\end{tabular}

The element $f_{33}$ is a parameter on which the other elements of the matrix $\mathbf{F}$ depend. After adopting its value the solution which satisfies the condition (8), is obtained. By doing this, the second stage shown in the diagram of Fig. 2 , is completed.

\section{D IMAGE GENERATION WITH THE USE OF THE ANAGLYPHIC METHOD}

A fundamental matrix does not immediately determine the component images of a 3D image. According to formula (9) it is possible to determine the epipolar lines which correspond to each other (Fig. 4). We will not discuss epipolar lines now, and the reader is referred to the relevant literature $[8,9,10$, $18,19,29,32]$.

The web-based solution does not generate a 3D image for the whole area of the joint coverage, but only for the area selected by the user. This is done by indicating the area centre in the right and left images and by selecting its size, e.g. $500 \times 500$ pixels. The problem is that it is convenient to start the generating process from the corner. Let us determine such a corner for the right image. From the formula (7) we define the equation of the corresponding epipolar line in the left image and find the starting point in it. The coordinate $\mathrm{x} 1$, i.e. the number of the column, will be determined in a close relationship between the coordinates of the homologous points which have been identified earlier and used to establish a fundamental matrix. Adopting its form as:

$$
x_{1}=a_{0}+a_{1} x_{2}+a_{2} y_{2}
$$

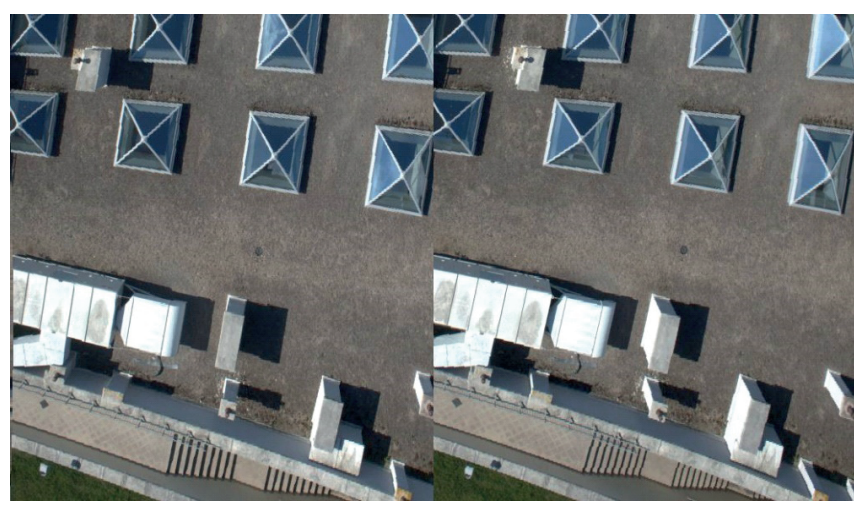

Fig. 4. Epipolar images

subsequent points are set by moving along the row in the first epipolar line in the right image. The line is determined by the selected starting point and the epipole. The corresponding point on the relevant epipolar line of the left image is selected on the basis of the jump al determined by means of the previously calculated relationship between the coordinates. 3D images are generated from the pyramid images without any additional change of scale. The levels of brightness of selected basic colour (blue and red) are interpolated by using the method of the nearest neighbour (Fig. 5). Resampling is to be avoided as this would deteriorate the sharpness of anaglyph and would take a longer time to generate it on the server.

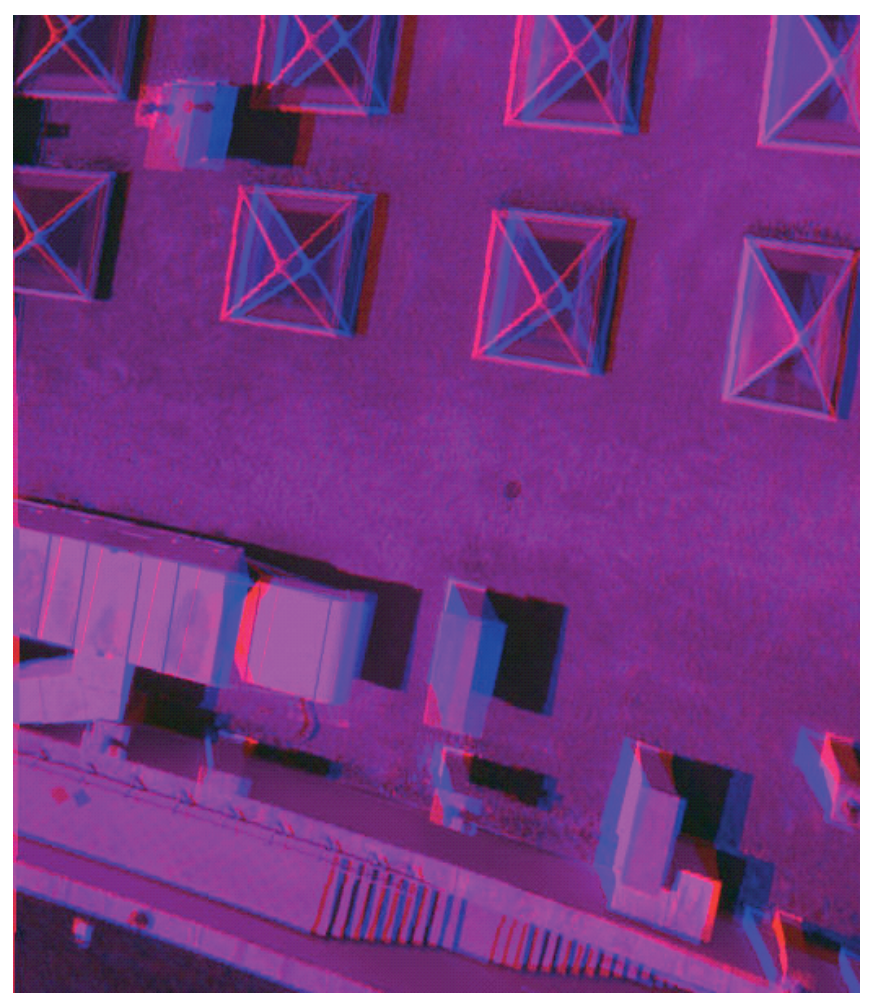

Fig. 5. An example of anaglyph displayed in Internet browser window. 


\section{THE VISUALIZATION OF 3D IMAGES WITH THE USE OF SHUTTER GLASSES METHOD.}

As the mentioned previously, the anaglyph 3D image is the easiest way of three-dimensional visualization. However the use of filters diminishes the quality of colour sensations. Using the active shutter $3 \mathrm{D}$ system to visualize is a better solution. To implement this method a computer with an appropriate graphic card, image display with 120 $\mathrm{Hz}$ frequency and shutter glasses, might be essential. Such hardware configuration is now also available in laptops. When we want to create the software for $3 \mathrm{D}$ visualization, the algorithms to display alternately colourful epipolar images for the left and right eye, should be used. Depending on what the graphics card and its driver enable, one uses the OpenGL or DirectX tools displaying images in full screen or window mode. It should be noted, however, that not every video card with a stereo option accepting the OpenGL has functions to buffer the stereoscopic images. If we do not write such computer program, the $3 \mathrm{D}$ browser normally installed together with the graphics card, can be used. In the case of the NVIDIA GeForce, GTX $460 \mathrm{M}$ is the 3D Vision Photo Viewer. This solution, however, requires generating a stereoscopic image as a jp file. The user of the program has three possibilities of visualization:

- as stereo-pair images, the left and right images side by side,

- as an anaglyph which has to have glasses with filters,

- one may also watch three-dimensional images through shutter glasses with the use of active shutter method controlled by the graphics card.

Images can be displayed in full screen or window mode. Among other programs supporting the jp format in the Windows system are: the VRex DepthStudio, StereoPhoto Maker 3DP Stereo Slideshow, Logipole Konvertor, XnView, 3DFantastic 3D Stereo Producer. More detailed information can be found at http://extension.nirsoft.net/jps. Another hardware solution for visualizing the three-dimensional image of the jp files is a TV set equipped with 3D function.

Generally speaking, the jps file is nothing but a modified jpg file. Images of the left and right stereo pair are included in a common jpg file. In the initial header part of the collection and a marker with information about the characteristics and location of the image components are placed. Full specifications of this form are available on the Internet at http://paulbourke.net/dataformats/stereoimage/spec. pdf. However, such type of collection might be created in a simplified manner.

We put the left and right images next to each other in the collection of any graphic format without compression such as the BMP. Each line of this set contains the first line of the first image and the second line of the second image. If the number of pixels in a line of the left and right images is equal, the total number of pixels in a line should be an even number. Then, the BMP format is converted to jpg format. In the end, the name of the extension from jpg to jps should be changed. Activity diagram for the image generating concept presented in this work will be similar to images like the one shown in Fig. 2. However in this case the procedure is modified in such a way that colourful epipolar images are built, the horizontal pair are assembled from them and left on the server. The user draws the image through the Internet in a separate process and displays it in his/her $3 \mathrm{D}$ browser.

\section{CONCLUSION}

The paper presents a method of generating epipolar images based on the method using the fundamental matrix. This method is applicable in case of using images taken with non-metric cameras. Epipolar images were used to produce stereoscopic images by using anaglyph methods and shutter system. The developed methods and algorithms were utilized in the web client-server application, which is available at http://stereo.uwm.edu.pl. The generated 3D images in the jps format can be found at http://stereo.uwm.edu.pl/stereo/. The above mentioned website contains applications that allow to test various solutions regarding the processing and transmitting of images over the Internet. The Web Server runs on request, as this solution is non-profit, i.e. given for scientific and educational purposes. The solutions in question are not prepared for distribution or subject to other marketing activities. The presented solution - as a concept and practical implementation - can be an excellent enrichment of the set of tools for the inspection of ports, including cargo ships and cargo handling.

The solutions are actual achievements of these authors and , besides practical usefulness, have also high educational merits. It is hoped that they contribute to the development and popularization of photogrammetric technology.

\section{REFERENCES}

1. Bielewicz, E., Gorski, J.: Shells with random geometric imperfections simulation - based approach. International Journal of Non-Linear Mechanics, 2002, Vol. 37, Iss. 4-5, pp.777-784, DOI: 10.1016/S0020-7462(01)00098-1

2. Burdziakowski, P., Szulwic, J.: A commercial of the shelf components for an unmanned air vehicle photogrammetry. $16^{\text {th }}$ International Multidisciplinary Scientific GeoConference SGEM 2016, www.sgem.org, SGEM2016 Conference Proceedings, ISBN 978-619-7105-59-9 / ISSN 1314-2704, June 28 - July 6, 2016, Book 2 ,Vol. 2, pp. 739-746, DOI: 10.5593/SGEM2016/B22/S10.095

3. Cho, W., Schenk, T. \& Madanim, M.: Resampling Digital Imagery to Epipolar Geometry. Proceedings of XVIIth ISPRS Congress Technical Commission III: Mathematical Analysis of Data, Washington, D.C., USA, ISPRS Archives, 1992, Volume XXiX, Part B3, pp. 404-408. 
4. Eisenbeiss, H.: UAV photogrammetry. Diss. ETH No.18515, Institute of Geodesy and Photogrammetry, Zurich, Switzerland, Mitteilungen, 2009, No.105. p. 235.

5. Elias, R.: Projective Geometry for Three-Dimensional Computer Vision. Multiple View Geometry in Computer Vision. Proceedings of Seventh World Multi-conference on Systemics, Cybernetics and Informatics, SCI'03. Orlando, USA, 2003, Vol. V, pp. 99-104.

6. Förstner, W.: New orientation procedures. The International Archives of Photogrammetry and Remote Sensing, 2000, Vol. XXXIII-B3A, pp. 297-304.

7. Górski, J., Mikulski, T., Oziębło M., Winkelmann K.: Effect of geometric imperfections on aluminium silo capacities. Stahlbau, 2015, Vol. 84, iss. 1, pp.52-57

8. Hartley, R., Zisserman, A.: Multiple View Geometry in Computer Vision. Cambridge University Press, Cambridge, UK, 2000.

9. Hartley, R.I.: In defense of the eight-point algorithm. IEEE Transactions on Pattern Analysis and Machine Intelligence, , 1997, Vol. 19, Iss. 6 , pp. 580-593.

10. Janowski, A., Nagrodzka-Godycka, K., Szulwic, J., Ziolkowski, P.: Remote sensing and photogrammetry techniques in diagnostics of concrete structures. Computers and Concrete, 2016, Vol. 18, Iss. 3, pp. 405-420, DOI: 10.12989/cac.2016.18.3.405

11. Janowski, A., Nowak, A., et al.: Mobile Indicators in GIS and GPS Positioning Accuracy in Cities. Lecture Notes in Computer Science, 2014, Vol. 8537, pp. 309-318, DOI: 10.1007/978-3-319-08729-0_31

12. Kaliński, K. J., Buchholz, C.: HILS for the design of threewheeled mobile platform motion surveillance system with a use of energy performance index. Solid State Phenomena, 2013 , Vol. 198, pp. 90-95.

13. Kaliński, K., Mazur, M.: Optimal control of 2-wheeled mobile robot at energy performance index. Mechanical Systems and Signal Processing, 2016 ,Vol. 70-71, pp. 373-386.

14. Kozak, J., Tarelko, W.: Case study of masts damage of the sail training vessel Pogoria. Engineering Failure Analysis. , 2011, Vol. 18, Iss. 3, pp. 819-827

15. Litwin, W.: Water lubricated marine stern tube bearings - attempt at estimating hydrodynamic capacity. ASME/STLE 19-21.10.2009, Proceedings of the ASME/ STLE International Joint Tribology Conference, 2010. DOI: 10.1115/IJTC2009-15068
16. Longuet-Higgins, H.: A computer algorithm for reconstructing a scene from two projections. Nature, 1982 ,Vol. 293, pp. 133-135.

17. Luczak, M., Manzato, S., Peeters, B., Branner, K., Berring, P., Kahsin, M.: Updating finite element model of a wind turbine blade section using experimental modal analysis results. Shock and Vibration, Vol. 2014, iss. 1, pp.71-82

18. Luong, Q.T.: Fundamental matrix and self-calibration. PhD Thesis, University of Paris, Orsay, 1992.

19. Luong, Q.T., Faugeras, O.D.: The fundamental matrix: Theory, algorithms, and stability analysis. International Journal of Computer Vision, 1996, Vol. 17, Iss. 1, pp. 43-75, DOI: 10.1007/BF00127818.

20. McGlone, J.C., Mikhail, E.M, Bethel, J. \& Mullen, R.: Manual of Photogrammetry. Fifth edition. American Society for Photogrammetry and Remote Sensing, Maryland, USA , 2004.

21. Nejadasl, F.K., Lindenbergh, R.: Sequential and automatic image-sequence registration of road areas monitored from a hovering helicopter. Sensors, 2014, Vol. 14, Iss. 9, pp. 16630-16650, DOI:10.3390/s140916630.

22. Paszotta, Z., Szulwic, J., Szumilo, M.: Internet photogrammetry as a tool for e-learning. $8^{\text {th }}$ International Conference of Education, Research and Innovation, 2015, ICERI2015, ISBN: 978-84-608-2657-6, pp. 4565-4573

23. Paszotta, Z., Szumilo, M.: A web-based approach for online digital terrain model and orthoimage generation. International Archives of the Photogrammetry Remote Sensing and Spatial Information Sciences, 2010, Vol. 38-4, Iss. W13, WebMGS 2010: $1^{\text {st }}$ International Workshop on Pervasive Web Mapping, Geoprocessing and Services, Como, Italy, 2010.08.26-27, ISSN 2194-9034.

24. Press, W., Flannery, B., Teukolsky, S. \& Vetterling, W.: Numerical recipes in C: The Art of Scientific Computing. $2^{\text {nd }}$ ed., pp. 59-70, Cambridge University Press, UK. 1992.

25. Przyborski, M., Szczechowski, B., Szubiak, W., Szulwic J. \& Widerski, T.: Photogrammetric development of the threshold water at the dam on the Vistula river in Wloclawek from unmanned aerial vehicles (UAV). $15^{\text {th }}$ International Multidisciplinary Scientific Geoconference, SGEM 2015, Albena, Bulgaria, June 18-24, 2015. DOI: 10.5593/SGEM2015/B31/S12.063

26. Ruzgienè, B., Aksamitauskas, C., Daugèla, I., Prokopimas, S., Puodžiukas, V. \& Rekus, D.: UAV photogrammetry for road surface modeling. The Baltic Journal of Road and Bridge Engineering, Vilnius , Technika, , 2015, Vol X, No. 2, p. 151-158 DOI: 10.3846/bjrbe.2015.19. 
27. Soheilian, B., Paparoditis, N. \& Vallet, B.: Detection and $3 D$ reconstruction of traffic signs from multiple view color images. ISPRS Journal of Photogrammetry and Remote Sensing, 2013,Vol. 77, pp. 1-20, DOI:10.1016/j. isprsjprs.2012.11.009.

28. Sondej, M, Iwicki, P.; Wojcik, M. et al.: Stability analyses of a cylindrical steel silo with corrugated sheets and columns. Steel and Composite Structures, 2016, Vol. 20, Iss. 1, pp. 147-166, DOI: 10.12989/scs.2016.20.1.147

29. Szeliski, R.: Computer Vision Algorithms and Applications. Springer-Verlag, London, UK, 2011.

30. Tejchman, J., Wojcik, M.: Modelling of shear localization during confined granular flow in silos within non-local hypoplasticity. Powder Technology, 2009,Vol. 192, iss. 3, pp.298-310, DOI: 10.1016/j.powtec.2009.01.021

31. Unger, J., Reich, M. \& Heipke, C.: UAV-based photogrammetry: monitoring of a building zone 2014. The International Archives of the Photogrammetry, Remote Sensing and Spatial Information Sciences, Vol. XL-5, 2014 ISPRS Technical Commission V Symposium, 23-25 June 2014, Riva del Garda, Italy.

32. Wang, L., Liu, Z. \& Zhang, Z.: Efficient image features selection and weighting for fundamental matrix estimation. IET Computer Vision, 2016, Vol. 10, Iss. 1, pp. 67-78, DOI: 10.1049/iet-cvi.2014.0436.

33. Zhang, Z.Y.: Robust wide-baseline stereo from maximally stable extremal regions. International Journal of Computer Vision, 1998, Vol. 27, Iss. 2, pp. 161-195.

\section{CONTACT WITH TE AUTHORS}

Prof. Zygmunt Paszotta

e-mail:paszotta@uwm.edu.pl

Univeristy of Wamia and Mazury in Olsztyn

Faculty of Geodesy, Geospatial and Civil Engineering, Oczpowskiego 2, 10-718 Olsztyn

\section{Poland}

Ph.D. Malgorzata Szumilo

e-mail:malgorzata.szumilo@uwm.edu.pl Univeristy of Wamia and Mazury in Olsztyn Faculty of Geodesy, Geospatial and Civil Engineering, Oczpowskiego 2, 10-718 Olsztyn

\section{Poland}

Ph.D. Jakub Szulwic e-mail: szulwic@pg.gda.pl Gdansk University of Technology Faculty of Civil and Environmental Engineering, Narutowicza 11/12, 80-233 Gdansk

\section{Poland}

